\title{
Investigations into the opening of fractures during hydraulic testing using a hybrid-dimensional flow formulation
}

\author{
Patrick Schmidt $^{1}$ (1) $\cdot$ Holger Steeb ${ }^{1,3} \cdot$ Jörg Renner ${ }^{2}$
}

Received: 23 November 2020 / Accepted: 13 June 2021 / Published online: 30 July 2021

(c) The Author(s) 2021

\begin{abstract}
We applied a hybrid-dimensional flow model to pressure transients recorded during pumping experiments conducted at the Reiche Zeche underground research laboratory to study the opening behavior of fractures due to fluid injection. Two distinct types of pressure responses to flow-rate steps were identified that represent radial-symmetric and plane-axisymmetric flow regimes from a conventional pressure-diffusion perspective. We numerically modeled both using a radial-symmetric flow formulation for a fracture that comprises a non-linear constitutive relation for the contact mechanics governing reversible fracture surface interaction. The two types of pressure response can be modeled equally well. A sensitivity study revealed a positive correlation between fracture length and normal fracture stiffness that yield a match between field observations and numerical results. Decomposition of the acting normal stresses into stresses associated with the deformation state of the global fracture geometry and with the local contacts indicates that geometrically induced stresses contribute the more the lower the total effective normal stress and the shorter the fracture. Separating the contributions of the local contact mechanics and the overall fracture geometry to fracture normal stiffness indicates that the geometrical stiffness constitutes a lower bound for total stiffness; its relevance increases with decreasing fracture length. Our study demonstrates that non-linear hydro-mechanical coupling can lead to vastly different hydraulic responses and thus provides an alternative to conventional pressure-diffusion analysis that requires changes in flow regime to cover the full range of observations.
\end{abstract}

Keywords Hydro-mechanics of fractures · Hybrid-dimensional modeling · Fracture contact mechanics · Fracture stiffness · Hydraulic testing of fractures $\cdot$ Reiche Zeche underground research laboratory

This article is a part of the Topical Collection in Environmental Earth Sciences on "Sustainable Utilization of Geosystems" guest edited by Ulf Hünken, Peter Dietrich, and Olaf Kolditz.

\section{Patrick Schmidt}

patrick.schmidt@mechbau.uni-stuttgart.de

Holger Steeb

holger.steeb@mechbau.uni-stuttgart.de

Jörg Renner

joerg.renner@ ruhr-uni-bochum.de

1 Institute of Applied Mechanics (CE), University of Stuttgart, Pfaffenwaldring 7, 70569 Stuttgart, Germany

2 Institute of Geology, Mineralogy and Geophysics, Ruhr-Univerität Bochum, 44801 Bochum, Germany

3 Stuttgart Center for Simulation Science (SC SimTech), University of Stuttgart, Pfaffenwaldring 5a, 70569 Stuttgart, Germany

\section{Introduction}

Estimation of a reservoir's effective hydraulic properties requires a consistent analysis of experimentally determined pressure and flow transients (Muskat and Wyckoff 1937; Fetter 2001). For individual fractures, simple analytical models for pressure-diffusion have been applied when their intersection with boreholes classified them as axial or radial (Matthews 1961; Matthews and Russell 1967; Horne 1995; Bourdet et al. 1989). Analytical models based on solutions of the diffusion equation for constant flow-rate tests document distinct differences in pressure response for onedimensional and radial flow associated with axial and radial fractures, respectively. Rocks with a dense array of randomly oriented fractures may justify their treatment as porous media, leading to radial flow, too. Mathematically, the full range of responses can be addressed by regarding the dimension of the flow to be a parameter (Barker 1988). However, hydro-mechanical phenomena, such as reverse water-level 
fluctuations in distant monitoring wells (Rodrigues 1983; Kim and Parizek 1997) or insensitivity of pressure responses to increases in flow rates, so-called jacking (Quirion and Tournier 2010), cannot be reproduced by pressure-diffusion models and result in inaccurate approximations of the effective fracture characteristics (Vinci et al. 2014a; Murdoch and Germanovich 2006; Cappa et al. 2018). Despite the growing number of treatments of hydro-mechanical coupling (Murdoch and Germanovich 2006; Girault et al. 2015, 2016; Castelletto et al. 2015; Schmidt and Steeb 2019), the understanding of the influence of basic geometrical and mechanical properties of fractures on their hydraulic response to flow rate or pressure perturbations remains limited; a critical obstacle to, e.g., the development of geothermal energy provision from petrothermal reservoirs.

Non-local fracture deformations triggered by perturbations of the fluid pressure along a fracture induce changes in permeability and volume of fractures with a direct impact on flow and storage characteristics and therefore on how the perturbations evolve with time and spread in space (Vinci et al. 2014b, a; Quintal et al. 2015; Berre et al. 2019). Accounting for hydro-mechanical interaction throughout numerical fitting of pressure and flow-rate transients is a non-trivial task and requires consistent evaluation of the balance equations in an efficient manner. Evaluation of fracture opening or closing in response to a perturbation of the equilibrium state requires considering the acting normal stresses owing to their control on the mechanical interaction between the fracture surfaces in contact. For example, large numbers of single Hertzian contacts have been invoked to characterize the mechanical interaction of two mated fracture surfaces (Timoshenko and Goodier 1987; Greenwood et al. 1966; Cook 1992). Responses of these contacts to changes in shear and normal stress result in changes of the effective fracture aperture (Goodman 1976; Bandis et al. 1983). Fracture opening does not depend on local contact mechanics alone but also on the geometrical stiffness of the fracture (Murdoch and Germanovich 2006). Despite the importance of fracture stiffness for the interpretation of pumping operations, little work has been devoted to decompose these two contributions.

Here, we analyze pressure transients from pumping tests conducted at the Reiche Zeche underground research laboratory, where the injection borehole penetrates a fractured rock. From a classical pressure-diffusion perspective, the hydraulic responses of the tested intervals mimic that of either radial-symmetric (positive-tangent group) or axialsymmetric (pressure-plateau group) fractures. Yet, logging and impression-packer results do not support this simple association of fracture geometry and hydraulic response. We employ a hydro-mechanical model considering radial-symmetric conditions, as applying for a radial fracture following a monolithic numerical implementation (Schmidt and Steeb
2019) to study the origin of the distinct pressure transients. Specifically, we studied the sensitivity of the hydro-mechanical model to the variation of characteristic fracture properties to identify best fits to the field data and the interdependence between the characteristic fracture properties.

\section{Test site and experimental approach}

\section{The Reiche Zeche underground research laboratory}

As part of the research program of STIMTEC, a cooperative project investigating the creation and growth of fractures in crystalline rocks to develop and optimize hydraulic STIMulation TEChniques (Dresen et al. 2019; Renner 2020), we performed hydraulic tests in the research mine Reiche Zeche (Rich Mine), Freiberg (Germany). The average depth below surface is about $130 \mathrm{~m}$ at the test site. The foliation of the fine- to medium-grained biotite gneiss dips $5^{\circ}-15^{\circ}$ in southeast direction. The gneiss is penetrated by fairly randomly oriented joints with an average separation of several decimeters. Fracture counting on retrieved cores yield $4.4 \pm 2.5$ $1 / \mathrm{m}$, but intact sections with a length of $1-2 \mathrm{~m}$ occur. In the test volume of about $40 \mathrm{~m} \times 50 \mathrm{~m} \times 20 \mathrm{~m}, 2-3$ steeply dipping, east-west trending damage zones were identified with a variable width between decimeters and a few meters.

The injection borehole BH10 with a length of $63 \mathrm{~m}$ and a radius of $0.038 \mathrm{~m}$ has a strike of $\mathrm{N} 31^{\circ} \mathrm{E}$ and a dip of $15^{\circ}$ from the horizontal, and thus, the borehole axis intersects the foliation at an angle of $20^{\circ}-30^{\circ}$. Ultrasonic transmission of the test volume as well as laboratory experiments on cores revealed a pronounced anisotropy in elastic parameters. Ultrasonic velocities are up to $20 \%$ faster in the direction of the foliation than perpendicular to it. Dynamic and static Young's moduli in the two directions differ by $10-15 \%$, with the low modulus observed for loading perpendicular to the foliation (Adero 2020).

\section{Experimental procedure}

Experiments were performed with a double-packer probe of Solexperts GmbH, Bochum, Germany, consisting of two inflatable packers isolating an injection interval of about 0.7 $\mathrm{m}$ length. The probe is equipped with uphole and downhole pressure gauges, and an uphole flowmeter, all sampled with 0.2 s. Flow rates measured uphole, i.e., outside of the borehole at the pump, were corrected for the storage capacity of the injection system to derive the true flow into the rock. The storage capacity was determined in a calibration experiment, for which the probe was inserted in a hollow steel cylinder.

The uniformly applied pumping protocol comprised a sequence consisting of (a) injection (with rates of 2-10 l/ min) until breakdown pressure was reached, the fracking, 
and subsequent shut-in phase, (b) three repeat injections, the refracs, with moderate rates of $3 \mathrm{l} / \mathrm{min}$ at maximum, each again followed by a shut-in phase, and (c) step-rate tests involving several phases of injection with constant flow rates, successively increased from below $1 \mathrm{l} / \mathrm{min}$ to about $5 \mathrm{l} / \mathrm{min}$. The pressure response in these step-rate tests constrains the jacking pressure, the fluid pressure at which the fracture(s) intersecting the borehole wall open. Opening is indicated by a significant increase in injectivity, and the ratio between flow rate and pressure. Impression-packer tests were performed after the entire pumping sequence to document fracture traces on the borehole wall.

\section{Intervals and selected data sets}

The data used here represent part of the results of the steprate tests performed in six intervals at depths of $24.6 \mathrm{~m}$, $40.6 \mathrm{~m}, 49.7 \mathrm{~m}, 51.6 \mathrm{~m}, 55.7 \mathrm{~m}$, and $56.5 \mathrm{~m}$. Logging before and after fluid injection with an acoustic televiewer and the impression-packer tests revealed pre-existing and induced fractures with a range of orientations (Table 1). We consider the circumferential fracture traces to represent radial fractures, even though they do not intersect the borehole axis at a right angle as strictly required. In addition, the traces classified as "axial" do not match this end-member geometry in a strict sense, but their tilt to the borehole axis is typical of en-echelon hydro-fractures occurring in boreholes that do not follow a principal stress axis (Zoback 2007). Actually, the short traces of interval $51.6 \mathrm{~m}$ are not well constrained at all. Furthermore, it is impossible to associate the observed pressure transients with a specific fracture trace when intervals exhibit multiple traces. This situation is not unusual but representative of what an interpreter typically faces when tests are performed in crystalline rocks.

We selected three to five of the first low flow-rate steps for the six intervals (Table 1, Fig. 1). The selection aimed to restrict to pressure and flow-rate couples, for which the proposed elastic model most likely applies. For some intervals, seismic activity was observed, and therefore, its absence during flow-rate steps could be used as criterion for "elastic" response. The pressure transients induced by the step-wise increase of flow rate differ for the six intervals.
Table 1 Interval characteristics

Fig. 1 The step-rate test data selected from the six intervals are divided in the pressureplateau group labeled with $M^{\mathrm{p}}$ and the positive-tangent group labeled with $M^{\mathrm{t}}$. The dark blue lines represent the recorded pressure data, the dark green lines the step-wise increasing flow-rate, and the dotted grey lines represent tangents to the pressure transient at the end of a flow-rate step

\begin{tabular}{lllll}
\hline Depth $(\mathrm{m})$ & Label $^{\dagger}$ & ${t_{1 / 3}^{\mathrm{p}}{ }^{\dagger}(\mathrm{s})}^{\mathrm{si}}{ }^{\mathrm{T}}(\mathrm{s})$ & Orientation of fracture traces \\
\hline 24.6 & $M_{a}^{\mathrm{t}}$ & $\gtrsim 433$ & $\gg 226$ & 1 parabola-shaped, induced \\
40.6 & $M_{b}^{\mathrm{t}}$ & 10 & $>170$ & 1 pre-existing circumferential; 2 axial, induced \\
49.7 & $M_{b}^{\mathrm{p}}$ & 24 & 8 & $\begin{array}{c}\text { 1 pre-existing, circumferential; 2 parabola-shaped, } \\
\text { pre-existing; 1 pair axial, induced }\end{array}$ \\
51.6 & $M_{a}^{\mathrm{p}}$ & 7 & 3 & $\begin{array}{l}\text { Several short axial } \\
55.7\end{array}$ \\
56.5 & $M_{c}^{\mathrm{t}}$ & 6 & 28 & 1 pre-existing circumferential; 1 pair axial, induced \\
& $M_{c}^{\mathrm{p}}$ & 3 & 33 & 1 pre-existing circumferential; 1 axial, induced \\
\hline
\end{tabular}

${ }^{\dagger}$ Classification of data set (Fig. 1)

${ }^{\ddagger}$ Time it took for a pressure pulse to decay by $1 / 3$ before the stimulation phase

TTime it took for pressure to decay by $1 / 2$ during the shut-in phase after the step-rate test
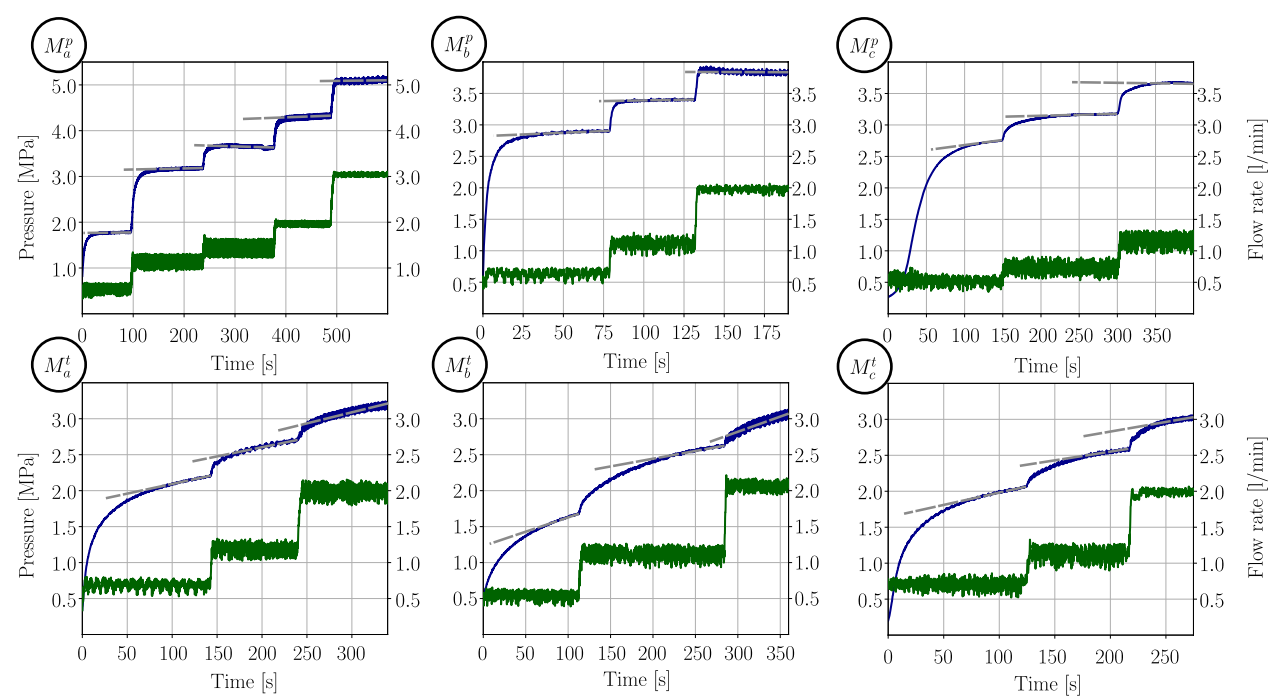
We distinguish two groups of pressure evolution during a step. Pressure responses with flat tangents are evident in data sets $M_{a}^{\mathrm{p}}$ to $M_{c}^{\mathrm{p}}$, a subset of our data that we will address as "pressure-plateau group". In contrast, the data sets $M_{a}^{\mathrm{t}}$ to $M_{c}^{\mathrm{t}}$ exhibit continuously increasing pressure, the "positivetangents group". For either group, however, the sensitivity of pressure level to flow rate diminishes with increasing flow rate, the observation interpreted as jacking.

\section{Numerical method}

When the aim is characterization rather than modification, hydraulic testing of fractures is performed below critical pressures for fracture extension, e.g., indicated by a decrease in injection pressure during constant-rate pumping. Breakdown is often related to tensile hydro-fracturing or when occurring over extended time periods or in a succession of small drops probably related to shearing events, either possibly accompanied by characteristic seismic activity. For tests performed at moderate injection pressures, fracture length can thus be treated constant and effects of changes in shear stress and therefore shear stiffness can be neglected. Fractures induced by hydraulic fracturing are expected to be oriented normal to the direction of the least principal (compressive) stress (Hubbert and Willis 1957), so that they intrinsically fulfill the assumption of negligible shear stress. In the context of hydraulic characterization of fractures, their contact mechanics may thus be reduced to an account of their normal stiffness (Pyrak-Nolte and Morris 2000). Hence, we apply a hydro-mechanical model considering the constitutive relation of normal contact following a monolithic numerical implementation (Schmidt and Steeb 2019) for the numerical determination of characteristic fracture parameters, initial width or aperture $\delta_{0}^{\text {hyd }}$, and normal stiffness parameter $E_{\mathrm{Fr}}$. The third characteristic parameter, the fracture length $l_{\mathrm{Fr}}$, is an element of the modeled fracturedomain discretization. The model's central aspects are recapitulated in the following, before details of the performed parameter search are presented.

\section{Governing equations}

Flow processes of weakly compressible, viscous fluids in high-aspect ratio fractures motivate the assumption of creeping flow conditions between two locally parallel plates, for which the balance of momentum reduces to a Poiseuille-type formulation (Witherspoon et al. 1980; Vinci et al. 2014a), i.e., the relative fluid velocity $\mathbf{w}_{\mathrm{f}}$ is proportional to the pressure gradient $\operatorname{grad} p$. In our continuum description, the associated cubic law $\mathbf{w}_{\mathfrak{f}}=-\frac{\left(\delta^{\mathrm{hyd}}(\mathbf{u})\right)^{2}}{12 \eta^{\ddagger R}} \operatorname{grad} p=:-\frac{k_{F r}^{\mathfrak{g}}}{\eta^{\uparrow R}} \operatorname{grad} p$,

is locally evaluated in the fracture domain $\Gamma^{F r}$, i.e., on the level of a material point $\mathcal{P}(\mathbf{x}, t)$, where $\mathbf{x}$ denotes its position vector, $\mathbf{u}(\mathbf{x}, t)=\mathbf{x}-\mathbf{X}$ the fracture deformation relative to the reference position vector $\mathbf{X}, t$ time, and $\eta^{f R}$ the dynamic fluid viscosity. The locally evaluated, deformationdependent permeability is identified as $k_{F r}^{\text {b }}(\mathbf{x}, t)=\left(\delta^{\text {hyd }}\right)^{2} / 12$ considering $\delta^{\text {hyd }}(\mathbf{u}(\mathbf{x}, t))$ to be the local effective hydraulic fracture aperture.

The hybrid-dimensional formulation is obtained by inserting the balance of momentum into the balance of mass, derived for a deformable fracture. The outcome of a dimensional analysis of the resulting partial differential equations suggests that quadratic and convective terms are negligible (Vinci et al. 2014a, b, 2015); the accordingly reduced hydromechanical governing equation reads

$$
\underbrace{\frac{\partial p}{\partial t}}_{\text {I) }}-\underbrace{\frac{\left(\delta^{\text {hyd }}\right)^{2}}{12 \eta^{\mathfrak{i} R} \beta^{\tilde{f}}} \operatorname{div}(\operatorname{grad} p)}_{\text {II })}+\underbrace{\frac{1}{\delta^{\text {hyd }} \beta^{\mathfrak{f}} \frac{\partial \delta^{\text {hyd }}}{\partial t}}}_{\text {III })}=\underbrace{\frac{q_{l k}}{\delta^{\text {hyd }} \beta^{\tilde{f}}}}_{\text {IV })} \text {, }
$$

comprising a transient I), a diffusion II), a coupling III), and a leak-off term IV), where $\beta^{\text {f }}$ denotes the fluid compressibility, and $q_{l k}$ leak-off, i.e., the flow-rate from the fracture into the surrounding rock mass. The deformation-dependent effective fracture aperture $\delta^{\text {hyd }}(\mathbf{u}(\mathbf{x}, t))$ contributes to the characteristic diffusion process by term II) and to volume changes of the fluid domain by term III), which strongly couples the solution of the fracture-flow domain to the deformation state of the surrounding matrix.

The rock matrix surrounding the fracture might be treated by purely elastic or by biphasic poro-elastic, e.g., Biot's theory (Biot 1941), formulations depending on the application in mind. For the typically substantial difference in the characteristic times of pressure diffusion in the fracture and in a surrounding crystalline rock, a biphasic description results in oscillations of the pore-pressure solution, when time discretization and material properties are chosen in the relevant range to model the conducted field experiments. Hence, this work refrains from treating the matrix by Biot's coupled poro-elastic theory but approximates the material behavior with Gassmann's low-frequency result (Gassmann 1951; Mavko et al. 2009).

The intact gneiss exhibits a permeability $<10^{-20} \mathrm{~m}^{2}$ (Adero 2020). Thus, leak-off from a fracture, into which fluid is injected from a borehole, into the "surrounding" is controlled by its intersection with other fractures. The hydraulic testing in BH10 revealed that the pre-existing fractures in the gneiss exhibit vastly variable hydraulic properties, as for example evidenced by the results of the pressure-pulse tests (Table 1). We 
thus face a range of possible scenarios for the induced or preexisting fractures intersecting the borehole. They may intersect only poorly permeable pre-existing fractures or linking up with a highly permeable pre-existing fracture. We consider either scenario to be suitable for an approximate description that neglects leak-off. For the second scenario, our modeling will simply gain the equivalent properties of a single fracture, since a variation of properties along a fracture is not tackled, and thus, a distinction of "individual" fracture segments composing a conduit is not possible. Neglecting leak-off likely overestimates "effective" length, because all of the injected fluid volume has to be stored in the fracture. Applying a single fracture model with fixed geometry to the encountered spectrum of fractures (Table 1) intends to test the versatility of the model and to determine equivalent fracture properties in a consistent way.

\section{Constitutive relations}

Traditionally, normal-contact models are expressed in terms of fracture deformation relative to the position corresponding to the first, stress-free contact of the two fracture surfaces, describing fracture closing by positive deformation values (Bandis et al. 1983; Gens et al. 1990). For the response of the fracture to changes in normal stress, we use a modified nonlinear-elastic constitutive relation based on the model proposed by Gens et al. (1990) and Segura and Carol (2008)

$\sigma_{\mathrm{N}}^{\mathrm{FR}}=E^{\mathrm{Fr}} \frac{U^{\mathrm{e}}}{U^{\max }-U^{\mathrm{e}}}$,

that characterizes the normal elastic deformation $U^{\mathrm{e}}$ of an interface with two parameters, the initial stiffness at vanishing normal stress, $E^{\mathrm{Fr}}$, and the maximum displacement for infinite stress $U^{\max }$. To be consistent with the governing flow Eq. (2), we formulate (3) in terms of relative aperture changes

$$
\begin{aligned}
U^{\mathrm{e}} & =-\left(\delta^{\mathrm{hyd}}-\delta_{0}^{\mathrm{hyd}}\right)=-\left(\delta^{\mathrm{mech}}-\delta_{0}^{\mathrm{mech}}\right)=-\Delta \delta, \\
U^{\mathrm{max}} & =-\Delta \delta_{\max }=-\left(\delta_{\min }^{\mathrm{mech}}-\delta_{0}^{\mathrm{mech}}\right),
\end{aligned}
$$

where the fracture deformation $U^{\mathrm{e}}$ is defined as changes of the effective hydraulic and mechanical aperture $\delta^{\text {hyd }}$ and $\delta^{\text {mech }}$ relative to their initial values $\delta_{0}^{\text {hyd }}$ and $\delta_{0}^{\text {mech }}$, respectively. The maximal deformation $U^{\max }$ is defined with respect to the difference between the minimal mechanical fracture aperture $\delta_{\min }^{\mathrm{mech}}$, approached for infinite normal stress, and the initial mechanical aperture $\delta_{0}^{\text {mech }}>\delta_{\min }^{\text {mech }}$ (Fig. 2). Neither absolute values of nor changes in mechanical and hydraulic apertures of fractures do have to coincide; particularly true once contact is established and the effective values of these aperture measures strongly depend on contact details and percolation characteristics in the fracture plane (PyrakNolte et al. 1988). To account for differences in deformationinduced changes of the mechanical and hydraulic fracture properties, we introduce the dimensionless parameter $s_{0}$. The parameter defines a relative deviation $\delta_{0}^{\text {mech }}=\delta_{0}^{\text {hyd }} / s_{0}$ of the initial mechanical aperture $\delta_{0}^{\text {mech }}$ from the initial hydraulic aperture $\delta_{0}^{\text {hyd }}$. For $s_{0}=1$, the initial hydraulic aperture coincides with the initial mechanical aperture $\delta_{0}^{\text {mech }}=\delta_{0}^{\text {hyd }}$, and the minimal mechanical aperture becomes equivalent to the minimal hydraulic aperture $\delta_{\min }^{\text {mech }}=\delta_{\min }^{\text {hyd }}$. Requiring $s_{0}>1$ ensures $\delta_{\min }^{\text {hyd }}>\delta_{\min }^{\text {mech }}$. The resulting hydraulic and mechanical fracture apertures are then expressed as

$$
\begin{aligned}
\delta^{\text {hyd }} & =\delta_{0}^{\text {hyd }}+\Delta \delta, \\
\delta^{\text {mech }} & =\delta_{0}^{\text {hyd }} / s_{0}+\Delta \delta .
\end{aligned}
$$

Inserting (5) into (4) and then into (3) gives

$$
\sigma_{\mathrm{N}}^{\mathrm{Fr}}=-E^{\mathrm{Fr}} \frac{\Delta \delta}{\left(\frac{\delta_{0}^{\text {hyd }}}{s_{0}}+\Delta \delta\right)-\delta_{\mathrm{min}}^{\mathrm{mech}}} .
$$

In principle, coupled hydro-mechanical simulations of deformable fractures require to numerically determine the equilibrium state of a fracture before the perturbation of its mechanical state, here associated with the pumping operations. Instead, we reformulate (6) using the aperture $\delta_{\mathrm{eq}}^{\text {mech }}=\delta_{\mathrm{eq}}^{\text {hyd }} / s_{0}$ that reflects the unperturbed in-situ normal stresses $\sigma_{\mathrm{N}, \mathrm{eq}}^{\mathrm{Fr}}$, where $\delta_{\mathrm{eq}}^{\mathrm{hyd}}$ is the hydraulic equilibrium aperture:

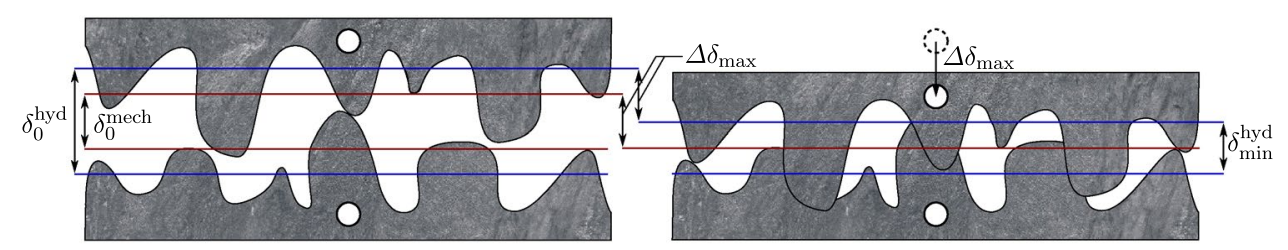

Fig. 2 Initial and maximum deformation state of two fracture surfaces in contact for $s_{0}>1$ and $\delta_{\min }^{\mathrm{mech}}=0$. The preferential direction of the flow $q$ is assumed to be normal to the sketched cross section of the fracture. Effective hydraulic and mechanical aperture represent the averaged local quantities on the continuum scale 


$$
\begin{aligned}
\Delta \sigma_{\mathrm{N}}^{\mathrm{Fr}} & =\sigma_{\mathrm{N}}^{\mathrm{Fr}}-\sigma_{\mathrm{N}, \mathrm{eq}}^{\mathrm{Fr}} \\
& =-E^{\mathrm{Fr}}\left[\frac{\Delta \delta}{\left(\frac{\delta_{0}^{\text {hyd }}}{s_{0}}+\Delta \delta\right)-\delta_{\text {min }}^{\text {mech }}}-\frac{\left(\delta_{\mathrm{eq}}^{\mathrm{mech}}-\frac{\delta_{0}^{\mathrm{hyd}}}{s_{0}}\right)}{\frac{\delta_{0}^{\text {hyd }}}{s_{0}}+\left(\delta_{\mathrm{eq}}^{\mathrm{mech}}-\frac{\delta_{0}^{\mathrm{hyd}}}{s_{0}}\right)-\delta_{\text {min }}^{\mathrm{mech}}}\right],
\end{aligned}
$$

i.e., we shift the reference state of the fracture to the in-situ stress level, the mechanical equilibrium state. Simple manipulations yield the relation in its implemented form by introducing the normal stiffness parameter of the equilibrium state $E_{\mathrm{eq}}^{\mathrm{Fr}}$ in a second step

$$
\begin{aligned}
\Delta \sigma_{\mathrm{N}}^{\mathrm{Fr}} & =-\left[E^{\mathrm{Fr}} \frac{\frac{\delta_{0}^{\mathrm{hyd}}}{s_{0}}-\delta_{\mathrm{min}}^{\mathrm{mech}}}{\delta_{\mathrm{eq}}^{\mathrm{mech}}-\delta_{\mathrm{min}}^{\mathrm{mech}}}\right] \frac{\Delta \delta_{\mathrm{eq}}}{\left(\delta_{\mathrm{eq}}^{\mathrm{mech}}+\Delta \delta_{\mathrm{eq}}\right)-\delta_{\mathrm{min}}^{\mathrm{mech}}} \\
& =-E_{\mathrm{eq}}^{\mathrm{Fr}} \frac{\Delta \delta_{\mathrm{eq}}}{\left(\frac{\delta_{\mathrm{eq}}^{\text {hyd }}}{s_{0}}+\Delta \delta_{\mathrm{eq}}\right)-\delta_{\mathrm{min}}^{\mathrm{mech}}}
\end{aligned}
$$

where $\Delta \delta_{\text {eq }}=\delta^{\text {mech }}-\delta_{\text {eq }}^{\text {mech }}$ defines the change in aperture from its equilibrium value.

The reduction of the numerical model to a single fracture embedded in the effectively impermeable surrounding gneiss results in negligible fluid exchange between fracture and solid domain similar to undrained conditions. Furthermore, the contribution of shear forces is negligible due to the low viscosity of the pore fluid, water, and the low frequency of the perturbations induced by the step-rate tests $(\ll 100 \mathrm{~Hz})$. Therefore, we treat the surrounding matrix by a single-phase formulation and neglect the leak-off term IV) in Eq. (2). The deformation state of the linear-elastic rock matrix, embedding the fracture, is then characterized by effective bulk modulus $K_{\text {eff }}$ and shear modulus $\mu_{\text {eff }}$
$K_{\mathrm{eff}}=\frac{\phi_{0}\left(\frac{1}{K^{3}}-\frac{1}{K^{\dagger}}\right)+\frac{1}{K^{3}}-\frac{1}{K}}{\frac{\phi_{0}}{K}\left(\frac{1}{K^{3}}-\frac{1}{K^{\dagger}}\right)+\frac{1}{K^{3}}\left(\frac{1}{K^{3}}-\frac{1}{K}\right)}$

$\mu_{\mathrm{eff}}=\mu$

representing Gassmann's low-frequency result (Gassmann 1951; Mavko et al. 2009). In Eq. (9), $\phi_{0}$ denotes the initial porosity of the porous matrix, $K^{\mathfrak{s}}$ the (average) modulus of the compressible grains composing the matrix, $K$ and $\mu$ the bulk and the shear modulus of the dry skeleton, and $K^{\mathfrak{f}}$ the bulk modulus of the fluid.

\section{Model parameters}

The flow model requires input values for the elastic parameters of the matrix, $K$ and $\mu$, the fluid bulk modulus $K^{\mathrm{f}}$, the equilibrium-fracture opening $\delta_{\mathrm{eq}}^{\text {hyd }}$, the minimal mechanical fracture opening $\delta_{\text {min }}^{\text {mech }}$, the equilibrium-normal stiffness parameter $E_{\mathrm{eq}}^{\mathrm{Fr}}$, the dimensionless contact parameter $s_{0}$, and flow-boundary conditions for the intersection of the fracture plane with the borehole, as prescribed by the individual experimental protocols followed for the tests in the six intervals. The chosen parameters are listed in Table 2; while Freiberg gneiss is anisotropic, see Adero (2020), for simplicity, we rely on representative isotropic material parameters. We employ a constant value of 4 for the parameter $s_{0}$, determined from exploratory calculations. The chosen value leads to changes in hydraulic aperture that are larger than the ones in mechanical aperture,

\begin{tabular}{|c|c|c|c|c|c|}
\hline Quantity & Value & Unit & Quantity & Value & Unit \\
\hline \multicolumn{6}{|l|}{ Rock parameters } \\
\hline Dry skeleton bulk modulus $K$ & $2.75 \times 10^{1}$ & (GPa) & Grain bulk modulus $K^{\text {s }}$ & $6.0 \times 10^{1}$ & $(\mathrm{GPa})$ \\
\hline Shear modulus $\mu$ & $1.7 \times 10^{1}$ & $(\mathrm{GPa})$ & Initial porosity $\phi_{0}$ & $1.0 \times 10^{-2}$ & $(-)$ \\
\hline Fluid compressibility $\beta^{\tilde{f}}$ & $4.17 \times 10^{-1}$ & $(1 / \mathrm{GPa})$ & Effective bulk modulus $K_{\text {eff }}$ & $4.25 \times 10^{1}$ & $(\mathrm{GPa})$ \\
\hline Effective shear modulus $\mu_{\text {eff }}$ & $1.7 \times 10^{1}$ & $(\mathrm{GPa})$ & & & \\
\hline \multicolumn{6}{|l|}{ Fracture parameters } \\
\hline Contact characteristic $s_{0}$ & 4.0 & $(-)$ & Fluid compressibility $\beta^{\tilde{f}}$ & $4.17 \times 10^{-1}$ & $(1 / \mathrm{GPa})$ \\
\hline Minimal mechanical opening $\delta_{\min }^{\text {mech }}$ & 0.0 & $(\mu \mathrm{m})$ & & & \\
\hline
\end{tabular}
addressing decreasing percolation in the fracture plane with increasing contact area. Fractures are assumed to be

Table 2 Parameters of the matrix and the fracture domain used for the numerical fitting of characteristic fracture properties 
mechanically closed once $\delta^{\text {mech }}$ approaches $\delta_{\min }^{\text {mech }}=0$. The remaining model parameters, the hydraulic equilibriumfracture aperture $\delta_{\text {eq }}^{\text {hyd }}$, and the equilibrium-fracture normal stiffness $E_{\mathrm{eq}}^{\mathrm{Fr}}$, along with the geometrical fracture property, its numerically discretized length $l_{\mathrm{Fr}}$, determine the effective hydraulic conductivity and the storage capacity of the fractures. The initial normal stress is determined by equilibrium aperture and initial stiffness via the constitutive relation. We seek optimized values for these three parameters by analyzing the misfit between numerical pressure transients and observed pressure transients.

The assumption of a radial-symmetric fracture geometry and a linear-elastic response of the poro-elastic matrix reduces the total number of degrees of freedom (DoF). This reduction of DoF results in a high efficiency of the method; simulations of transients require just several minutes on a standard desktop PC with the used numerical discretization corresponding to around 20,000 DoF for the whole set of modeled fractures.

\section{Quantification of misfit}

Identifying "the" best numerical fit requires examination of the evolution of the misfit between experimentally observed transients $\boldsymbol{p}_{\text {exp }}$ and the numerically modeled transients $\boldsymbol{p}_{\text {num }}$. We quantify misfit by a normalized $L_{2}$-error norm

$e_{L_{2}}=\frac{\left\|\boldsymbol{p}_{\text {num }}-\boldsymbol{p}_{\exp }\right\|_{2}}{\left\|\boldsymbol{p}_{\exp }\right\|_{2}}$,

i.e., misfit is reduced to a single scalar value for each considered parameter combination. Iso-surfaces of misfit in the three-dimensional space of the model parameters $\left\{\delta_{\mathrm{eq}}^{\mathrm{hyd}}, E_{\mathrm{eq}}^{\mathrm{Fr}}, l_{\mathrm{Fr}}\right\}$ were gained from interpolation between the discrete values of actually performed calculations.

\section{Strategy of parameter search}

The sensitivity of the model to its parameters was studied in a total of 1144 and 735 simulations for the pressure-plateau and the positive-tangent group, respectively. Numerical fits with a normalized error of approximately $e_{L_{2}} \leq 0.055$ correspond to absolute deviations between observed and modeled pressure continuously below $0.2 \mathrm{MPa}$ and are considered matches of the experimental observations in the light of the subsumed effects of flow-rate fluctuations due to irregularities of the pump, intrinsic accuracy of pressure sensors, and the correction of flow rate for storage capacity of the injection system. The investigated ranges of the individual parameters (Table 3) were defined based on an exploratory analysis starting from educated guesses. This exploratory search indicated the existence of a misfit minimum below the defined error of $e_{L_{2}} \leq 0.055$ whose location were then investigated further. For the subsequent analysis of the remaining sets of measurement data, knowledge about the existence of a local minimum motivated the direct search for parameter combinations resulting in an error of $e_{L_{2}} \leq 0.055$, corresponding to fits within uncertainty.

\section{Results}

The parameter study aimed at the identification of parameter combinations yielding a match between field data and numerical simulations to understand the characteristics of fractures responsible for the two distinct groups of pressure transients. In a first step, we focused on one data set of each group, the transient pressure response $M_{a}^{\mathrm{p}}$ obtained from hydraulic tests at $51.6 \mathrm{~m}$ borehole depth, representing the pressure-plateau group, and $M_{a}^{\mathrm{t}}$ corresponding to tests conducted at a borehole depth of $24.6 \mathrm{~m}$, representative for the pressure-tangent group, before we used the gained knowledge about the existence of a local error minimum to reduce the computational costs of the numerical fitting procedure for the remaining data sets by focusing on parameter combinations resulting in low error values.

\section{Parameter study}

\section{Pressure-plateau group}

The error surfaces of the pressure-plateau group possess an ellipsoid-like shape (Fig. 3); the surface enclosing numerical solutions with $e_{L_{2}}=0.0275$, representing matches of the observed transients within the estimated uncertainty, indicates the existence of an error minimum. The error evolution with fracture length ( $A_{\mathrm{I}}$ to $H_{\mathrm{I}}$ in Fig. 3 ) is consistent with the iso-surface plot, since the error reaches a minimum at an intermediate fracture length of $l_{\mathrm{Fr}}=50.0 \mathrm{~m}$. The error evolution is asymmetric around this minimum, and it increases
Table 3 Parameter ranges (min, $\max$ ) and increment (inc) for the studies of the model sensitivity for the pressure-plateau and pressure-tangent group

\begin{tabular}{|c|c|c|c|c|c|c|c|c|c|}
\hline \multirow[t]{2}{*}{ Group } & \multicolumn{3}{|c|}{$E_{\mathrm{eq}}^{\mathrm{Fr}}(\mathrm{MPa})$} & \multicolumn{3}{|c|}{$\delta_{\text {eq }}^{\text {hyd }}(\mu \mathrm{m})$} & \multicolumn{3}{|c|}{$l_{\mathrm{Fr}}(\mathrm{m})$} \\
\hline & Min & Max & Inc & $\overline{M i n}$ & Max & $\overline{\text { Inc }}$ & Min & Max & Inc \\
\hline Pressure-plateau group & 4.0 & 6.4 & 0.2 & 30.0 & 39.0 & 1.0 & 20.0 & 90.0 & 10.0 \\
\hline Positive-tangent group & 2.4 & 3.6 & 0.2 & 33.0 & 47.0 & 1.0 & 2.4 & 16.0 & 2.5 \\
\hline
\end{tabular}


Fig. 3 Top: visualization of iso-surfaces of misfit between observed and calculated pressure transients for the parameter study conducted on the experimental data set $M_{a}^{\mathrm{p}}$ representative for the pressureplateau group. Error surfaces are marked with the associated $e_{L_{2}}$-errors and parameter combinations relevant for detailed analysis of the error evolution are highlighted by labels $A_{\mathrm{I}}$ to $H_{\mathrm{I}}$. Bottom: comparison of observed and numerical pressure transients for the parameter combinations $A_{\mathrm{I}}$ to $H_{\mathrm{I}}$. (left)

The flow-rate boundary conditions are well matched by the numerical approach. (right) The errors of the numerical fits for parameter sets $A_{\mathrm{I}}$ to $H_{\mathrm{I}}$ exhibit a minimum. The legend at the bottom applies to all plots
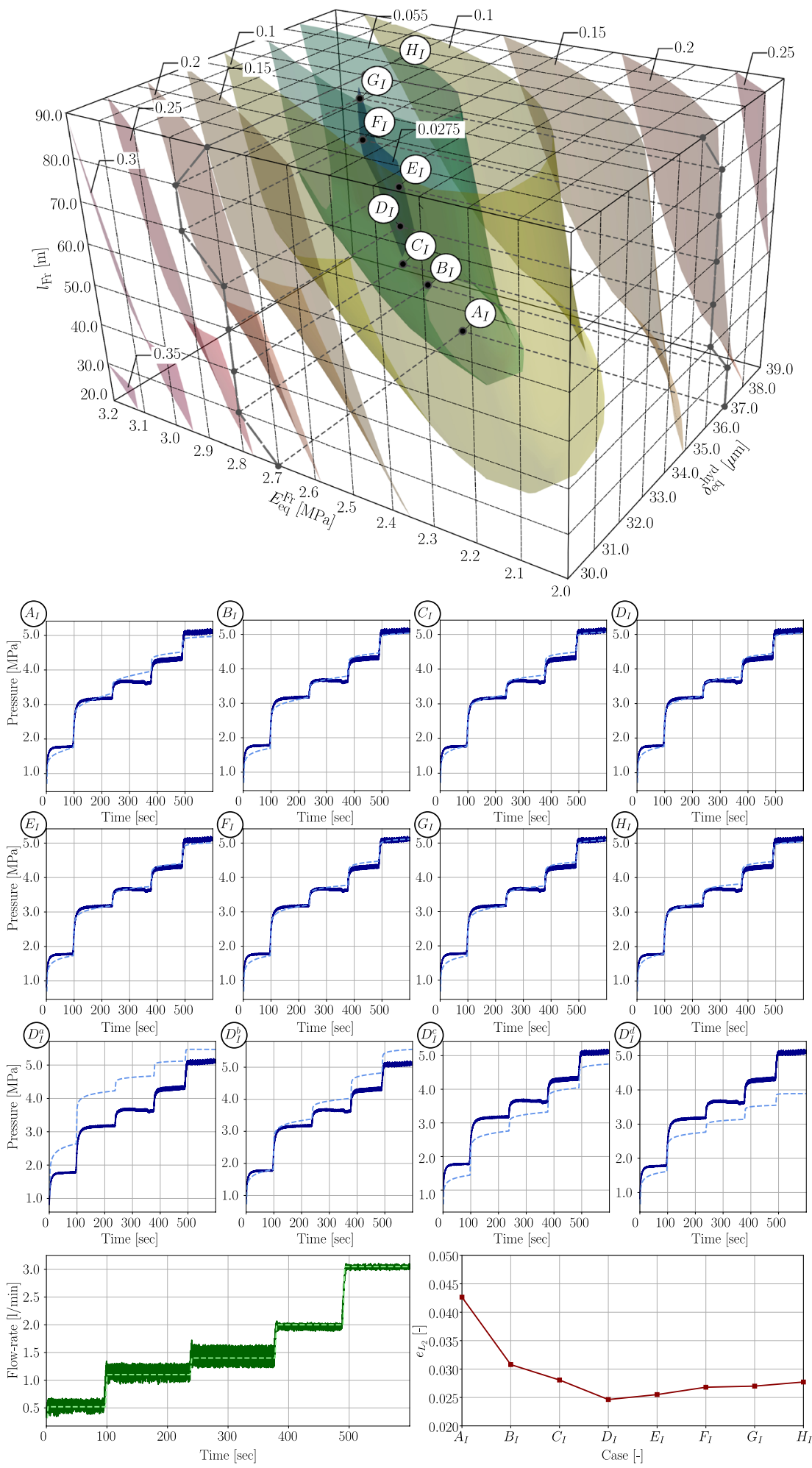

- . - . - . Numerical Pressure

Numerical Flowrate $\longrightarrow$ Experimental Flowrate 
less steep for fractures with an increasing than for fractures with a decreasing length. The corresponding unique error minimum in the parameter space occurs for the parameter combination $D_{\mathrm{I}}$, which consists of an hydraulic equilibriumfracture aperture $\delta_{\text {eq }}^{\text {hyd }}=36.0 \mu \mathrm{m}$, an equilibrium-fracture normal stiffness parameter of $E_{\mathrm{eq}}^{\mathrm{Fr}}=5.6 \mathrm{MPa}$, and a fracture length of $l_{\mathrm{Fr}}=50.0 \mathrm{~m}$. The model shows higher sensitivity to the equilibrium-fracture normal stiffness parameter and the hydraulic equilibrium aperture than to fracture length. Individual variations of the fracture stiffness and hydraulic equilibrium aperture relative to the values obtained for the identified minimum (exemplified by $D_{\mathrm{I}}^{a}$ to $D_{\mathrm{I}}^{d}$ in Fig. 3) result in pronounced under- and overestimation of the measured transients, respectively.

\section{Positive-tangents group}

For the positive-tangent group, the misfit surface identifying relevant parameter combinations with absolute differences to the measured data consistently below $0.2 \mathrm{MPa}$, defined by $e_{L_{2}} \leq 0.055$, consists of two connected ellipsoidal shapes with different axis-orientations. A single potential minimum is indicated by the closed iso-surface with $e_{L_{2}} \leq 0.03$. The error evolution with fracture length ( $A_{\mathrm{II}}$ to $G_{\mathrm{II}}$ in Fig. 4 ) confirms the existence of a minimum for the parameter set $B_{\mathrm{II}}$, consisting of an equilibrium-fracture normal stiffness parameter $E_{\text {eq }}^{\mathrm{Fr}}=2.8 \mathrm{MPa}$, an equilibrium aperture of $\delta_{\text {eq }}^{\text {hyd }}=42.0$ $\mu \mathrm{m}$, and a fracture length of $l_{\mathrm{Fr}}=4.75 \mathrm{~m}$. Large misfits result when fracture length decreases below $4.75 \mathrm{~m}$; however, misfit is less sensitive to variations in fracture length above this value. Variation of the equilibrium-fracture normal stiffness parameter $E_{\text {eq }}^{\mathrm{Fr}}$ and the hydraulic equilibrium aperture $\delta_{\text {eq }}^{\text {hyd }}$ relative to the parameter set $B_{\mathrm{II}}$ (i.e., parameter sets $B_{\mathrm{II}}^{a}$ to $B_{\mathrm{II}}^{d}$ in Fig. 4) reveals a higher sensitivity of the model to changes of the stiffness parameter than the hydraulic equilibrium aperture.

\section{Characteristic fracture properties}

For each of the further pressure-plateau and pressure-tangent data, parameter sets were found that result in fits with error values close to those obtained for the local minima in the two examples above (Fig. 5, Table 4). The error for data set $N_{c}^{\mathrm{p}}$ is exceptionally high compared to that of other sets when we do not neglect the first pumping step (Table 4) that involves a delayed pressure increase (Fig. 1). This interval looses water when isolated and has to be refilled after an extended shut-in period.

The elongated enclosing hull of the determined parameter combinations for the pressure-plateau group visualizes the recognized bias of fracture stiffness and equilibrium-fracture aperture with fracture length. For the positive-tangent group, we observed bias of the fracture stiffness with fracture length, but no correlation between equilibrium aperture and fracture length (Fig. 5, Table 4). Optimal parameters of the two groups occupy distinctly different volumes of the misfit space. Parameters determined for the pressure-plateau group correspond to long and stiff fractures, whereas the parameters determined for the pressure-tangent group coincide with short and compliant fractures.

\section{Discussion}

The numerical fitting of pressure transients identified a unique minimum corresponding to an optimal parameter combination in the range of investigated material parameters. The sensitivity analysis proofed increasing errors for changes of parameters relative to the set $D_{\mathrm{I}}$, which indicates that no further minima exist within realistic limits of the parameters. The model exhibits a high sensitivity to the equilibrium-fracture normal stiffness and the equilibriumfracture aperture, whereas simulated pressures are relatively insensitive to changes in fracture length.

\section{Characteristics of pressure groups}

The proposed hydro-mechanical model results in vastly different pressure transients depending on parameter choice and thus either group of observed transients, those with nearly constant pressures and those with continuously increasing pressure at constant flow rate, could be modeled equally well. For both pressure-transient groups, values of equilibrium aperture and equilibrium-normal stiffness parameter determined by the numerical fitting fall well within the range of previously discussed values (Klimczak et al. 2010; Schuite et al. 2017; Zangerl et al. 2008). The different pressure transients of the two groups require distinctly different length and stiffness to match the measurement data. The fracture lengths of meter-scale derived for the positive-tangent group are consistent with the spatial scale of the test volume and the dimensions of seismicity clouds observed during the corresponding stimulations. The decameter-scale fracture lengths modeled for the pressure-plateau group appear long at first glance. Yet, considering the shape of the misfit iso-surface of this group that documents an insensitivity of the model to changes in fracture length beyond a critical lower bound, fracture lengths barely exceeding $10 \mathrm{~m}$ cannot be excluded per-se. Furthermore, the model involves only a single fracture, neglecting leak-off into intersecting fracture systems and thus its application to data determines properties of an equivalent fracture potentially subsuming pre-existing fractures with a comparable or higher conductivity than that of the fracture intersecting the borehole. The 
Fig. 4 Top: a visualization of error surface plots corresponding to the parameter study conducted on the experimental data set $M_{a}^{\mathrm{t}}$ representative for the positive group is presented. Error surfaces are marked with the associated $e_{L_{2}}$-errors and parameter combinations relevant for detailed analysis of the error evolution are highlighted by labels $A_{\mathrm{II}}$ to $G_{\mathrm{II}}$. Bottom: numerical fits of the measured pressure transients corresponding to the highlighted parameter combinations $A_{\text {II }}$ to $G_{\text {II }}$ along with the corresponding fit of flow-rate boundary conditions are introduced. Errors of the numerical fits for parameter sets $A_{\mathrm{II}}$ to $G_{\mathrm{II}}$ are presented by means of a line plot. A legend introduces the corresponding quantities to the used line types at the bottom of the figure
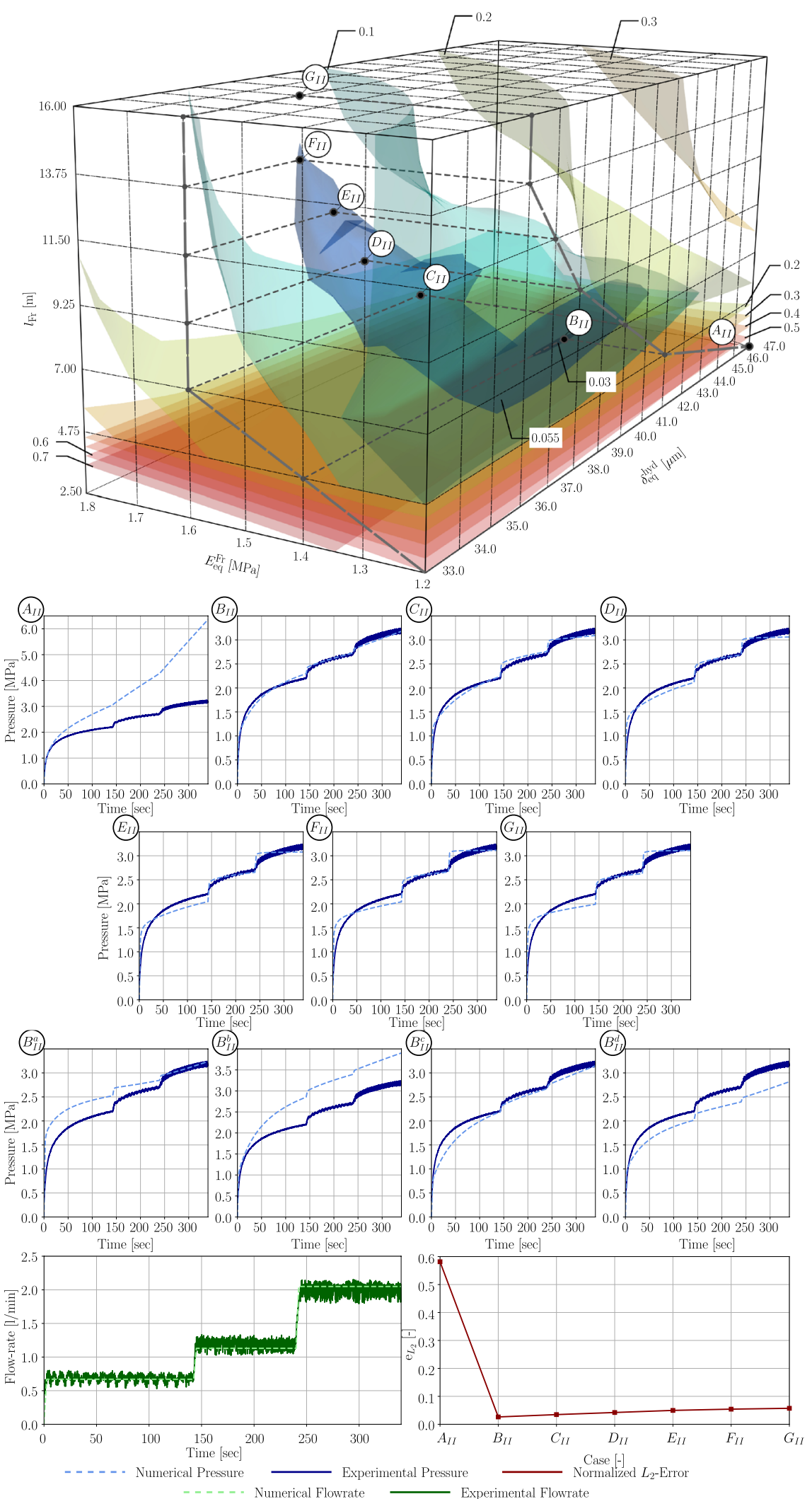

Numerical Flowrate $\longrightarrow$ Experimental Flowrate 
Table 4 Material parameters gained from numerical fitting of the measured pressure transients

\begin{tabular}{|c|c|c|c|c|c|}
\hline Depth & Fracture label & $\begin{array}{l}\text { Equ. fracture normal stiff- } \\
\text { ness par. } E_{\mathrm{eq}}^{\mathrm{Fr}}\end{array}$ & $\begin{array}{l}\text { Equilibrium aper- } \\
\text { ture } \delta_{\mathrm{eq}}^{\text {hyd }}\end{array}$ & Fracture length $l_{\mathrm{Fr}}$ & Error $e_{L_{2}}$ \\
\hline \multicolumn{6}{|c|}{ Pressure-plateau group } \\
\hline $51.6 \mathrm{~m}$ & $N_{a}^{\mathrm{p}}$ & $5.6 \mathrm{MPa}$ & $36.0 \mu \mathrm{m}$ & $50.0 \mathrm{~m}$ & 0.024 \\
\hline $55.7 \mathrm{~m}$ & $N_{b}^{\mathrm{p}}$ & $3.5 \mathrm{MPa}$ & $26.5 \mu \mathrm{m}$ & $10.0 \mathrm{~m}$ & 0.048 \\
\hline $56.5 \mathrm{~m}$ & $N_{c}^{\mathrm{p}}$ & $3.8 \mathrm{MPa}$ & $28.0 \mu \mathrm{m}$ & $15.0 \mathrm{~m}$ & $0.184 / 0.024^{1}$ \\
\hline \multicolumn{6}{|c|}{ Positive-tangent group } \\
\hline $24.6 \mathrm{~m}$ & $N_{a}^{\mathrm{t}}$ & $2.8 \mathrm{MPa}$ & $42.0 \mu \mathrm{m}$ & $4.75 \mathrm{~m}$ & 0.026 \\
\hline $40.6 \mathrm{~m}$ & $N_{b}^{\mathrm{t}}$ & $2.13 \mathrm{MPa}$ & $55.0 \mu \mathrm{m}$ & $3.7 \mathrm{~m}$ & 0.063 \\
\hline $49.7 \mathrm{~m}$ & $N_{c}^{\mathrm{t}}$ & $2.95 \mathrm{MPa}$ & $46.0 \mu \mathrm{m}$ & $5.4 \mathrm{~m}$ & 0.046 \\
\hline
\end{tabular}

${ }^{1}$ Including/excluding the first injection step biased by the necessity to refill the injection interval

interpretation that the distinct difference in effective fracture length derived for the two pressure-transient groups is an expression of the extent to which the fracture intersecting the borehole connected to pre-existing fractures and thus became an element of a larger conduit network qualitatively agrees with the pressure decay rates during shut-in after the step-rate tests (Table 1).

\section{Distribution of pressure along the fracture}

Knowing the distribution of fluid pressure along the fracture is a crucial pre-requisite for substantial stimulation modeling. Since our hydro-mechanical model includes the entire fracture, we can use the determined parameter sets to investigate the pressure distribution in the fracture at any point during the step-rate tests. We focus on the pressure states at the end of each applied flow-rate step for data sets $N_{a}^{\mathrm{p}}$ and $N_{b}^{\mathrm{t}}$, representative for their corresponding group, to examine whether the characteristics of the transients observed in the borehole bear information on the pressure distribution along the fracture.

For $N_{a}^{\mathrm{p}}$, the representative of the pressure-plateau group, pressure gradients along the fracture are higher than for $N_{b}^{\mathrm{t}}$ of the positive-tangent group, for which the pressure profile is almost flat, i.e., the pressure in the fracture is equilibrated during every stage of the pumping (Fig. 6). Thus, the shape of the transients of the injection pressure is opposite to the spatial variation of pressure in the fracture, and constant injection pressures are associated with significant pressure gradients, while injection pressures increasing with time are associated with momentarily constant pressures in the fractures. The significant difference in pressure distribution reflects the critical interrelation between local deformation and its consequences for local flow and storage. For the long fractures of the pressure-plateau group, the local deformation and thus permeability decrease with distance from the injection point, but storage of fluid is promoted close to the borehole where the fracture is already less stiff than at its end due to the increased fluid pressure. While constant along the relatively short fractures, the pressure increases during each flow-rate step and from step to step for the positivetangent group. The close to constant pressures document that pressure is not controlled by transport restrictions in the fractures but by their storage capacity, which is limited owing to the direct effect of fracture length on fracture volume and also on geometrical fracture stiffness, as detailed in the next section.

\section{Specific normal stiffness}

The contact mechanics of the six investigated fractures is uniquely determined by the parameters constrained by the modeling. Evaluating the constitutive relation (8) with the found equilibrium-fracture normal stiffness parameter $E_{\mathrm{eq}}^{\mathrm{Fr}}$ and the hydraulic equilibrium-fracture width $\delta_{\text {eq }}^{\text {hyd }}$ yields their opening and closure behavior when subjected to normal stresses deviating from the equilibrium stress (Fig. 7). The corresponding specific contact stiffnesses reflect the strong non-linearity of the constitutive relation; close to the equilibrium stress specific stiffness varies between $10^{2}$ and $10^{3} \mathrm{MPa} / \mathrm{mm}$ and thus falls well within the range of representative previous in-situ observations and laboratory studies (Schuite et al. 2017; Zangerl et al. 2008; PyrakNolte and Morris 2000). When extended toward increasing fracture contact, i.e., when effective normal stresses exceed the equilibrium in-situ stresses, the stiffness of all tested fractures converge to a narrow range of $2 \times 10^{3} \mathrm{MPa} /$ $\mathrm{mm}$ to $4 \times 10^{3} \mathrm{MPa} / \mathrm{mm}$.

The equilibrium-fracture normal stiffness parameter $E_{\mathrm{eq}}^{\mathrm{Fr}}$ provides a constraint on the equilibrium stress that the fractures experience in-situ. Since the obtained equilibriumfracture normal stiffness parameters of the pressure-plateau group are higher than the ones of the positive-tangent group, the predicted equilibrium-normal stresses for fractures of the plateau group, ranging between 3.5 and 5.6 $\mathrm{MPa}$, are larger 
Fig. 5 Top: comparison of numerical flow and pressure transients, corresponding to the set of parameter fits determined throughout the numerical fitting, to the experimentally recorded pressure and flow transients. Bottom: visualization of the determined parameter sets in a three-dimensional parameter space. The space spanned by parameter combinations associated with the pressure-plateau group is introduced by a blue hull and the space resulting from parameter sets of the positive-tangent group is limited by a grey hull
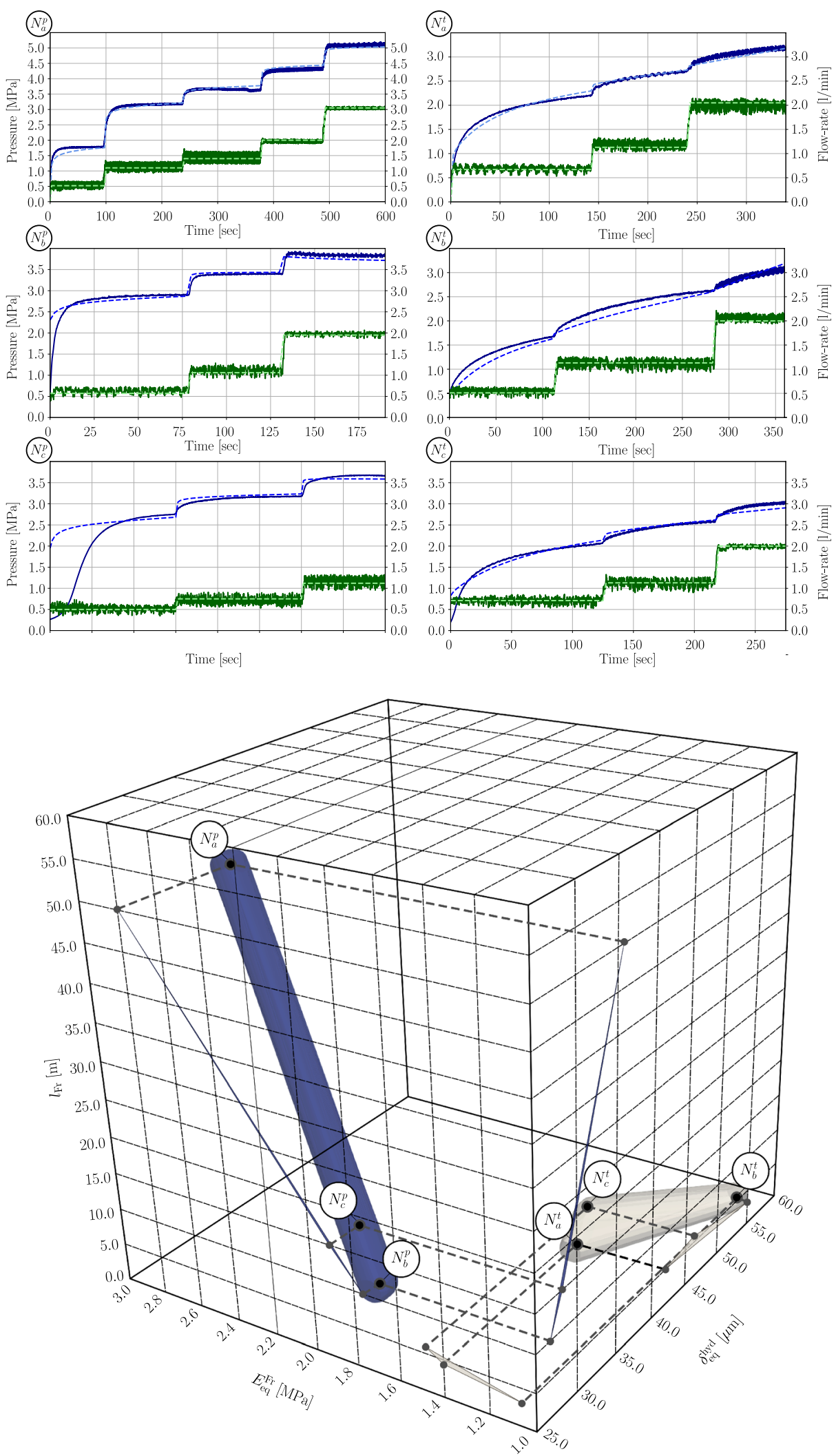
Fig. 6 Evolution of pressure distribution along the fractures at the end of each flow-rate step, represented by increasing line thickness with increasing step number $\mathrm{St}_{i}$, for numerical data set $N_{a}^{\mathrm{p}}$ of the pressure-plateau group (left) and data set $N_{b}^{\mathrm{t}}$ of the positive-tangent group (right)
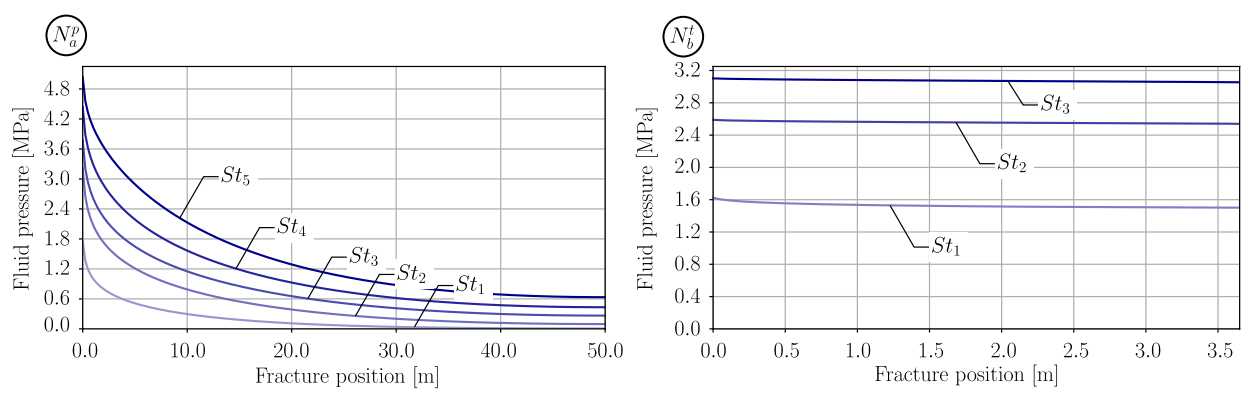
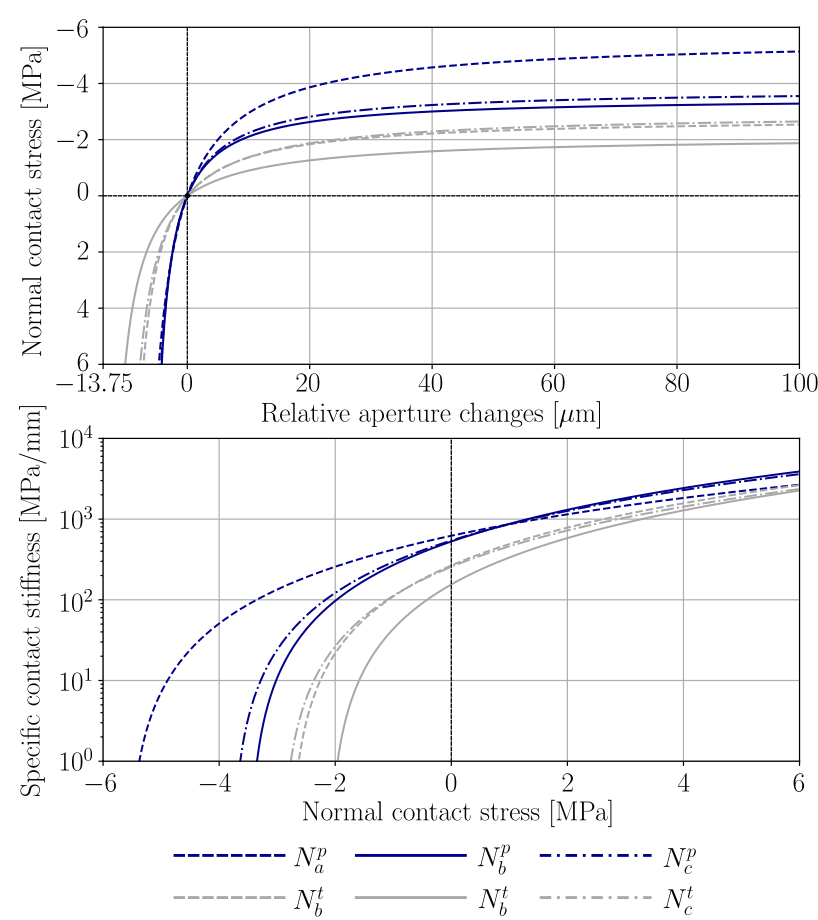

Fig. 7 Top: normal-contact stress $\sigma_{\mathrm{N}}^{\mathrm{Fr}}$ as a function of relative aperture changes $\Delta \delta$ gained from evaluating Eq. (8) with the best-fit parameters for the investigated pressure transients (Table 4). Bottom: semi-logarithmic representation of the specific contact stiffness $K_{\mathrm{N}}^{\mathrm{Fr}}$ as a function of the acting normal-contact stresses. Positive values indicate compressive stresses (relative to the equilibrium stress). The legend applies to top and bottom; specifically, dark blue lines represent data sets of the pressure-plateau group and grey lines that of the positive-tangent group

than the ones for fractures of the positive-tangent group, ranging from 2.1 to 2.8 $\mathrm{MPa}$. Magnitude and range of these predictions are consistent with the stress state inferred for the test volume at Reiche Zeche, where the overburden corresponds to a vertical stress of about 3.5 $\mathrm{MPa}$ (Adero 2020).

The contribution of the elastic medium, in which the fractures are embedded, to the stiffness of the entire system is conventionally addressed as geometrical stiffness
(Murdoch and Germanovich 2006; Vinci et al. 2014a). We evaluated the balance between contact stiffness and geometrical stiffness by numerical evaluation of constant fluid pressures in the range of the experimental pressure levels with an increment of $0.5 \mathrm{MPa}$ for the two "equivalent" fractures found by the modeling for intervals $51.6 \mathrm{~m}\left(M_{a}^{\mathrm{p}}\right)$ and $40.6 \mathrm{~m}\left(M_{b}^{\mathrm{t}}\right)$, representing the two pressure-transient groups and constituting the upper and lower bounds of the parameter space of optimal fits in terms of fracture length and normal stiffness parameter, respectively.

The prescribed levels of fluid pressure lead to local deformations according to the constitutive relation (8) and associated local normal-contact stresses $\sigma_{\mathrm{N}}^{\mathrm{Fr}}$, which we integrate over the fractures' lengths. Mechanical equilibrium across the fracture requires changes in fluid pressure and total normal stress to hold $\Delta p=\Delta \sigma_{\mathrm{N}}^{\text {Tot }}$. Thus, the mismatch between the applied fluid pressure and the numerically integrated normal-contact stresses corresponds to the normal stress exerted on the fracture by the deformation of the surrounding material, here addressed as geometrical normal stress $\sigma_{\mathrm{N}}^{\mathrm{G}}$. The decomposition of the changes in total acting normal stress

$\Delta \sigma_{\mathrm{N}}^{\mathrm{Tot}}=\Delta \sigma_{\mathrm{N}}^{\mathrm{Fr}}+\Delta \sigma_{\mathrm{N}}^{\mathrm{G}}$

gives changes in the geometrical stress as

$\Delta \sigma_{\mathrm{N}}^{\mathrm{G}}=\Delta p-\Delta \sigma_{\mathrm{N}}^{\mathrm{Fr}}$.

The stress balance differs for the two investigated fractures and varies with fluid pressure for an individual fracture (Fig. 8). For the long $(50 \mathrm{~m})$ fracture of the pressure-plateau group, force balance across the fracture is dominated by contact stresses, while the contribution of geometrical normal stress is significant for the short $(3.7 \mathrm{~m})$ fracture of the positive-tangent group, the more the higher the fluid pressure. The changing relative contributions result from the non-linearity of the normal-contact stress formulation introduced by Eq. (8).

We transfer the findings for the normal-stress decomposition (Fig. 8) to a corresponding decomposition of specific normal stiffness. The fracture contact normal stiffness is obtained by analytical evaluation of $K^{\mathrm{Fr}}=\partial \sigma_{N}^{\mathrm{Fr}} / \partial \delta^{\mathrm{Fr}}$ 


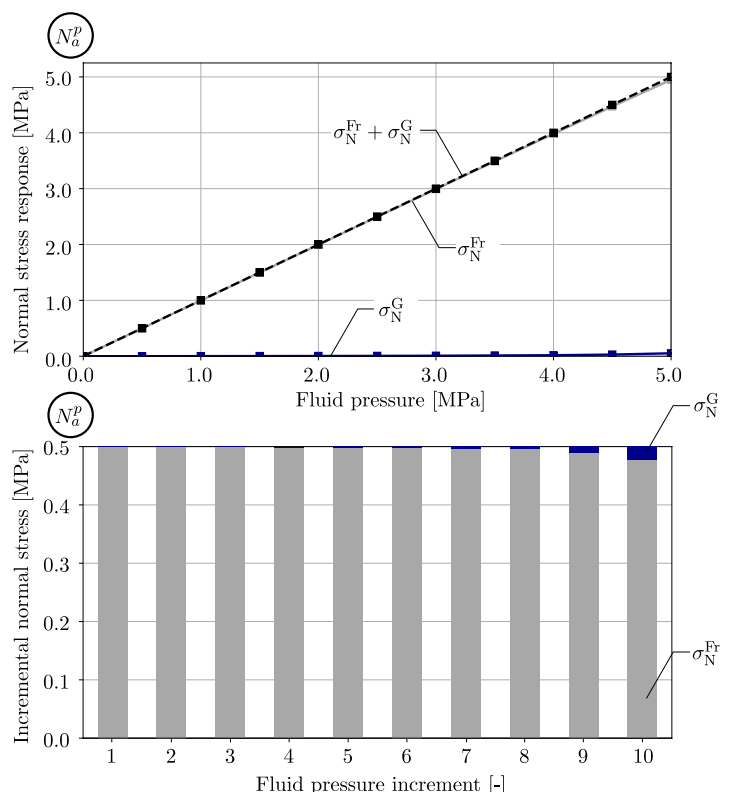

Fig. 8 Top: decomposition of the total acting normal stresses into geometrical $\sigma_{\mathrm{N}}^{\mathrm{G}}$ and normal contact stress $\sigma_{\mathrm{N}}^{\mathrm{Fr}}$ contributions as a function of the acting constant fluid pressure for numerical parameter sets obtained from numerical fits $N_{a}^{\mathrm{P}}$, representative for the pressure pla-
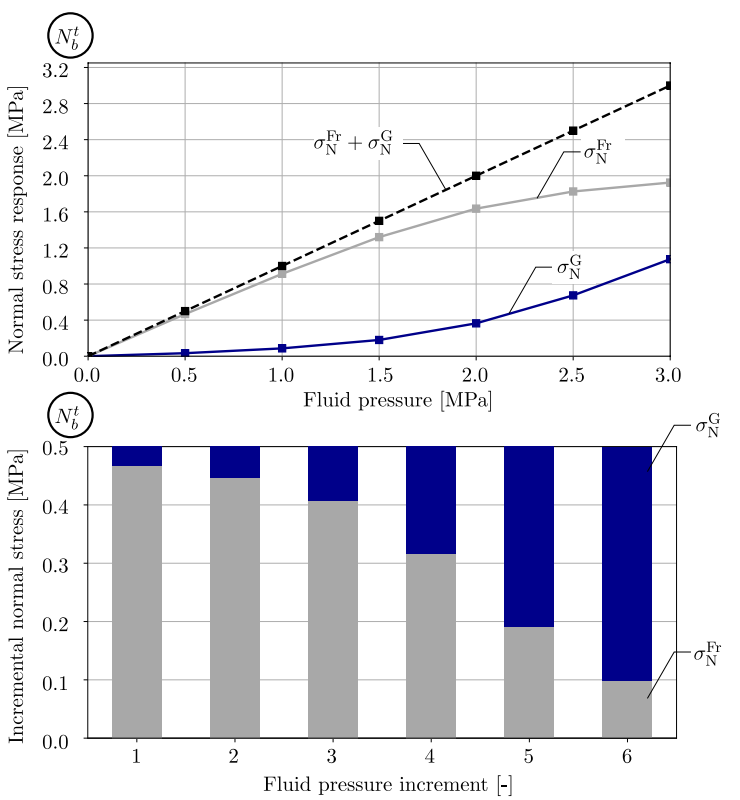

teau, and $N_{b}^{\mathrm{t}}$, representative for the positive-tangent group. Bottom: contribution of geometrical and normal-contact stresses for each incremental pressure increase
Fig. 9 Combined $\left(K_{\mathrm{N}}^{\mathrm{Com}}\right)$ specific fracture stiffness, i.e., the sum of decomposed geometrical $K_{\mathrm{N}}^{\mathrm{G}}$ and normal-contact stiffness $K_{\mathrm{N}}^{\mathrm{Fr}}$, as a function of fluid pressure calculated from results of the proposed hydro-mechanical modeling of data sets $N_{a}^{\mathrm{p}}$ and $N_{b}^{\mathrm{t}}$
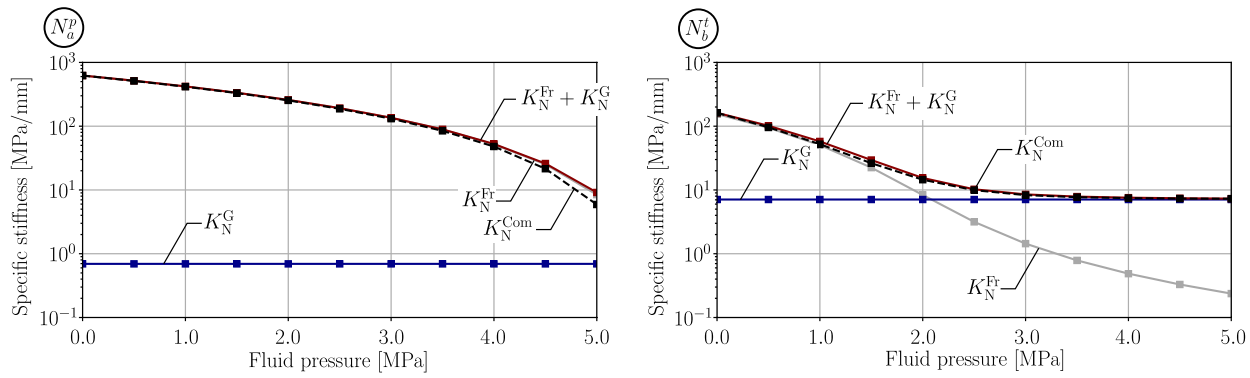

considering the fitted parameters. In a subsequent step, we separated the geometrical stiffness of the two investigated fractures by conducting a numerical analysis of their opening behavior under the assumption of negligible contact normal stresses, which results in $p=\sigma_{\mathrm{N}}^{\mathrm{G}}$. The discretized geometrical stiffness is then evaluated by calculating an averaged aperture and the discretized normal stress change, i.e., $K^{\mathrm{G}}=\Delta \sigma_{N}^{\mathrm{G}} / \Delta \delta^{\mathrm{G}}$. The combined stiffness is numerically determined by $K^{\mathrm{Com}}=\Delta \sigma_{N}^{\text {Tot }} / \Delta \delta^{\mathrm{Com}}$. Since the relation between $\sigma_{N}^{\text {Tot }}=p, \sigma_{N}^{\mathrm{G}}$, and $\sigma_{N}^{\mathrm{Fr}}$ is known from the stress decomposition (Fig. 8), the resulting stiffness components can be combined to express the stiffness of the combined model for a uniform fluid pressure.

The sum of transformed geometrical and contact normal stiffness agrees with the combined stiffness (Fig. 9) lending support to the assumptions made regarding the transformation of different stress states to the acting effective normal stress. Geometrical stiffness is found to be negligible for data set $N_{p}^{a}$ of the pressure-plateau group, for which the combined specific stiffness is well approximated by the contact stiffness, i.e., fluid pressure and acting contact stresses balance (Fig. 7). In contrast, the combined specific stiffness for data set $N_{b}^{\mathrm{t}}$, the representative of the positive-tangent group, is a superposition of both stiffness components converging toward the geometrical stiffness with increasing fluid pressure. In fact, the geometrical stiffness forms the lower bound for combined stiffness. The contribution of the geometrical stiffness to the total fracture stiffness is highest for fluid pressures above the identified asymptotic stress values of the contact model, i.e., at the onset of separation of the fracture halves. 


\section{Conclusions}

We numerically modeled the opening characteristics of fractures during in-situ hydraulic tests using a hydromechanical flow model implemented for radial fractures with non-linear contact mechanics and without leak-off. Systematic variations of experimentally observed pressure transients lead us to distinguish two groups, with continuously (positive-tangent) and step-wise rising (pressureplateau) pressure response to step-wise increases in flow rate. Our parameter study unveiled the role of fracture length, equilibrium-normal stiffness parameter, and equilibrium-fracture aperture for borehole-pressure transients. The proposed hydro-mechanical coupling can explain the strikingly different pressure transients within experimental uncertainty and thus provides a perspective to the response of fractures to pumping operations alternative to the traditional pressure-diffusion analyses, which relate the distinct pressure groups to differences in flow regime associated with differences in the orientation of the fracture relative to the borehole. This alternative explanation bears significant consequences for the modeling of energy provision from pertrothermal reservoirs, in which the fractures constitute the prime conduits for the transport agent of the heat.

The identified minima in mismatch between observed and calculated pressure transients correspond to different fracture properties for the two groups. We noticed a bias between fracture length and fracture normal stiffness resulting in a specific mismatch for the positive-tangent group. Pressure plateaus are characteristic of relatively long and stiff fractures, while relatively short and compliant fractures lead to continuously increasing injection pressures. Equilibrium-fracture apertures do not differ significantly between the two groups, a plausible result considering that the tested fractures are embedded in the same host rock. The pressure distribution along the fractures differs significantly for the two groups of pressure transients; pronounced non-linear pressure distributions develop in the long fractures of the pressure-plateau group during injection, while the pressure in the short fractures of the positive-tangent group remains close to the injection pressure along their entire length. Our observations on pressure distribution motivate to investigate the validity of the common practices of normal stress estimation from shut-in and jacking pressures. The stress balance across fractures and its relation to fluid distribution in them is central for modeling failure and seismicity. A full analysis of the potential for shear failure will require to expand our model by shear stresses and assocaited stiffness.

Throughout the performed step-rate tests, fluid injection results predominantly in opening of fractures. Evaluation of the constitutive relation with the determined fracture parameters allowed us to investigate the contributions of local contacts and overall fracture geometry to stress balance and thus bulk stiffness. With decreasing effective stress, the role of the contacts diminishes and total stiffness approaches the lower bound constituted by the geometrical stiffness.

The proposed hydro-mechanical model exhibits diminished sensitivity to fracture length when a flow-rate step results in a constant injection pressure. Thus, extending the pumping duration will not only help to discriminate between the alternatives of flow regime vs. hydro-mechanical effects, but may also reduce uncertainty of model parameters in case pressure ultimately deviates from an early plateau, an observation that could not be explained by the diffusion approaches. Future numerical work should explore different scenarios for the relation between mechanical and hydraulic apertures and its evolution with changes in effective normal stresses.

Acknowledgements Jörg Renner is indebted to Felix Becker, Gerd Klee, and Florian Seebald of Solexperts GmbH for the collegial atmosphere during the field testing. Thomas Grelle and Carlos Lehne, and Katja Hesse of LIAG, Hannover, are thanked for performing the televiewer logging and processing the log data, respectively.

Funding Open Access funding enabled and organized by Projekt DEAL. The authors gratefully acknowledge the funding provided by the German Federal Ministry of Education and Research (BMBF) for the STIMTEC project (subprojects HYSPALAB and SPATZ, Grant numbers 03A0015A and 03G0901A) and the GeomInt (I \& II) project (Grant numbers 03A0004E and 03G0899E), within the BMBF Geoscientific Research Program "Geo:N Geosciences for Sustainability". Holger Steeb thanks the DFG for supporting this work under Grant no. SFB 1313 (Project no. 327154368).

Availability of data and materials The data that support the findings of this study are available from the corresponding author, Patrick Schmidt, upon request.

Code availability Not applicable.

\section{Declerations}

Conflict of interest Not applicable.

Open Access This article is licensed under a Creative Commons Attribution 4.0 International License, which permits use, sharing, adaptation, distribution and reproduction in any medium or format, as long as you give appropriate credit to the original author(s) and the source, provide a link to the Creative Commons licence, and indicate if changes were made. The images or other third party material in this article are included in the article's Creative Commons licence, unless indicated otherwise in a credit line to the material. If material is not included in the article's Creative Commons licence and your intended use is not permitted by statutory regulation or exceeds the permitted use, you will need to obtain permission directly from the copyright holder. To view a copy of this licence, visit http://creativecommons.org/licenses/by/4.0/. 


\section{References}

Adero BA (2020) Experimental investigations of mechanical anisotropy of Freiberg gneiss: implications for hydraulic stimulation. Dissertation, Ruhr-Universität Bochum

Bandis S, Lumsden A, Barton N (1983) Fundamentals of rock joint deformation. Int J Rock Mech Min Sci Geomech Abstr 20(6):249-268

Barker JA (1988) A generalized radial flow model for hydraulic tests in fractured rock. Water Resour Res 24(10):1796-1804

Berre I, Doster F, Keilegavlen E (2019) Flow in fractured porous media: a review of conceptual models and discretization approaches. Transp Porous Med 130:215-236

Biot MA (1941) General theory of three-dimensional consolidation. J Appl Phys 12(2):155-164

Bourdet D, Ayoub J, Pirard Y (1989) Use of pressure derivative in well test interpretation. SPE Form Eval 4:293-302

Cappa F, Guglielmi Y, Nussbaum C, Birkholzer J (2018) On the relationship between fault permeability increases, induced stress perturbation, and the growth of aseismic slip during fluid injection. Geophys Res Lett 45(20):11012-11020

Castelletto N, White JA, Tchelepi HA (2015) Accuracy and convergence properties of the fixed-stress iterative solution of two-way coupled poromechanics. Int J Numer Anal Methods Geomech 39(14):1593-1618

Cook N (1992) Natural joints in rock: mechanical, hydraulic and seismic behaviour and properties under normal stress. Int J Rock Mech Min Sci Geomech Abstr 29(3):198-223

Dresen G, Renner J, Bohnhoff M, Konietzki H, Kwiatek G, Plenkers K, Klee G, Backers T (2019) STIMTEC: a mine-back experiment in the Reiche Zeche underground laboratory. Geophysical Research Abstracts vol 21. EGU2019-9357, EGU General Assembly, Vienna

Fetter C (2001) Applied hydrogeology, vol 4. Prentice Hall, Hoboken

Gassmann F (1951) Über die Elastizität poröser Medien: Vierteljahrsschrift der Naturforschenden Gesellschaft in Zürich, pp 1-23

Gens A, Carol I, Alonso E (1990) A constitutive model for rock joints formulation and numerical implementation. Comput Geotech 9(1):3-20

Girault V, Wheeler MF, Ganis B, Mear ME (2015) A lubrication fracture model in a poro-elastic medium. Math Models Methods Appl Sci 25(04):587-645

Girault V, Kumar K, Wheeler MF (2016) Convergence of iterative coupling of geomechanics with flow in a fractured poroelastic medium. Comput Geosci 20(5):997-1011

Goodman RE (1976) Methods of geological engineering in discontinuous rocks. West Publishing Company, Eagan

Greenwood JA, Williamson JBP, Bowden FP (1966) Contact of nominally flat surfaces. Proc R Soc Lond A Math Phys Sci 295(1442):300-319

Horne RN (1995) Modern well test analysis. Petroway Inc, Palo Alto

Hubbert MK, Willis DG (1957) Mechanics of hydraulic fracturing. Trans AIME 210(01):153-168

Kim JM, Parizek RR (1997) Numerical simulation of the Noordbergum effect resulting from groundwater pumping in a layered aquifer system. J Hydrol 202(1):231-243

Klimczak C, Schultz RA, Parashar R, Reeves DM (2010) Cubic law with aperture-length correlation: implications for network scale fluid flow. Hydrogeol J 18(4):851-862

Matthews C (1961) Analysis of pressure build-up and flow test data. J Pet Technol 13:862-870

Matthews CS, Russell DG (1967) Pressure buildup and flow tests in wells, vol 1. Henry L. Doherty Memorial Fund of AIME, New York
Mavko G, Mukerji T, Dvorkin J (2009) The rock physics handbook: tools for seismic analysis of porous media. Cambridge University Press, Cambridge

Murdoch LC, Germanovich LN (2006) Analysis of a deformable fracture in permeable material. Int J Numer Anal Methods Geomech 30(6):529-561

Muskat M, Wyckoff R (1937) The flow of homogeneous fluids through porous media. International series in physics. McGraw-Hill, New York

Pyrak-Nolte LJ, Morris JP (2000) Single fractures under normal stress: The relation between fracture specific stiffness and fluid flow. Int J Rock Mech Min Sci 37(1):245-262

Pyrak-Nolte LJ, Cook NGW, Nolte DD (1988) Fluid percolation through single fractures. Geophys Res Lett 15(11):1247-1250

Quintal B, Rubino JG, Caspari E, Holliger K (2015) A simple hydromechanical approach to simulate squirt-type flow at any scale. SEG Int Exposition Annu Meet 2015:3224-3228

Quirion M, Tournier JP (2010) Hydraulic jacking tests in crystalline rocks for hydroelectric projects in Quebec. ISRM International Symposium on In-Situ Rock Stress, Canada

Renner J (2020) STIMTEC: a mine-scale hydraulic stimulation experiment of anisotropic metamorphic rock with evaluation by mineback drilling. ARMA Newsletter

Rodrigues JD (1983) The Noordbergum effect and characterization of aquitards at the Rio Maior mining project. Groundwater 21(2):200-207

Schmidt P, Steeb H (2019) Numerical aspects of hydro-mechanical coupling of fluid-filled fractures using hybrid-dimensional element formulations and non-conformal meshes. Int J Geomath 10(1): 14

Schuite J, Longuevergne L, Bour O, Guihéneuf N, Becker MW, Cole M, Burbey TJ, Lavenant N, Boudin F (2017) Combining periodic hydraulic tests and surface tilt measurements to explore in situ fracture hydromechanics. J Geophys Res Solid Earth 122(8):6046-6066

Segura JM, Carol I (2008) Coupled HM analysis using zero-thickness interface elements with double nodes-part II: verification and application. Int $\mathrm{J}$ Numer Anal Methods Geomech 32(18):2103-2123

Timoshenko SP, Goodier JN (1987) Theory of elasticity. Engineering societies monographs. McGraw-Hill, New York

Vinci C, Renner J, Steeb H (2014a) A hybrid-dimensional approach for an efficient numerical modeling of the hydro-mechanics of fractures. Water Resour Res 50(2):1616-1635

Vinci C, Renner J, Steeb H (2014b) On attenuation of seismic waves associated with flow in fractures. Geophys Res Lett 41(21):7515-7523

Vinci C, Steeb H, Renner J (2015) The imprint of hydro-mechanics of fractures in periodic pumping tests. Geophys J Int 202(3):1613-1626

Witherspoon PA, Wang JSY, Iwai K, Gale JE (1980) Validity of cubic law for fluid flow in a deformable rock fracture. Water Resour Res 16(6):1016-1024

Zangerl C, Evans K, Eberhardt E, Loew S (2008) Normal stiffness of fractures in granitic rock: a compilation of laboratory and in-situ experiments. Int J Rock Mech Min Sci 45(8):1500-1507

Zoback MD (2007) Reservoir geomechanics. Cambridge University Press, Cambridge

Publisher's Note Springer Nature remains neutral with regard to jurisdictional claims in published maps and institutional affiliations. 